\title{
Capitaloceno, luchas por lo común y disputas por otros términos de interdependencia en el tejido de la vida. Reflexiones desde América Latina.
}

\section{Mina Lorena Navarro Trujillo Y LuCÍA LINSALATA*}

\section{RESUMEN}

Las reflexiones que aquí se presentan nacen de las preocupaciones del área de investigación de "entramados comunitarios y formas de lo político" en torno a lo que hoy en América Latina significa defender la vida para un amplio y variado abanico de procesos organizativos y luchas comunitarias en medio de las renovadas dinámicas de apropiación, despojo, devastación y degradación de las naturalezas humanas y no humanas que las violentas lógicas de acumulación impulsan sin parar. Esta inquietud nos ha llevado a la tarea de dotarnos de una mirada analítica, ecológica, holística y relacional en torno a la noción de vida, que hemos ido componiendo en diálogo con la perspectiva de la ecología-mundo, la ecología política latinoamericana y la apuesta de algunas tradiciones del feminismo por poner en el centro la vida. En este texto, a modo de síntesis parciales, presentamos lo que, desde nuestras propias inquietudes políticas, implica pensar la vida, el Capitaloceno y las disputas planteadas por una multiplicidad de luchas en defensa de lo común con base en diversas investigaciones en diferentes países de América Latina, en particular en México y Bolivia, pero también en Ecuador, Guatemala, Colombia y Uruguay. El texto se compone de tres apartados. En el primero, explicamos qué entendemos por condición de interdependencia y cómo, a partir de esta idea, recuperamos la noción de trama/tejido de la vida propuesta por diferentes autores. En el segundo, nos preguntamos por la vida que el proyecto moderno-capitalista ha ido produciendo a partir de la lógica de dominio de carácter antropocéntrico, patriarcal y colonial y los modos en los que se ha buscado reorganizar la condición de interdependencia, poniendo a trabajar a las naturalezas humanas y no humanas para garantizar la lógica de acumulación. Un ejemplo a través del cual ilustramos estas dinámicas es la gestión capitalista de las relaciones de interdependencia en torno al agua en tiempos neoliberales. Y finalmente, exponemos sobre la base de numerosas investigaciones, enfocadas principalmente en experiencias comunitarias en oposición a algún proyecto extractivista, nuestro acercamiento al antagonismo social y la disputa que entablan las luchas por lo común en América Latina para defender la vida y gestionar las relaciones de interdependencia en contradicción con los términos de coproducción capitalistas..

\section{Palabras Clave}

Interdependencia; perspectiva ecología-mundo; producción de lo común; luchas en defensa de la vida; América Latina.

\section{TitLe}

Capitalocene, struggles for the common and disputes for other terms of interdependence in the web of life. Reflections from Latin America

\section{EXTENDED Abstract}

The reflections presented here are part of the concerns of the "Communitarian Weavings and Political Forms Research Group" at the Benemerita Universidad Autónoma de Puebla (Autonomous University of Puebla), in Mexico, in relation to what it means in Latin America to defend life through a wide and varied range of organizational processes and community struggles in the midst of the renewed dynamics of appropriation, dispossession, devastation and degradation of the human
* Mina Lorena NAVARRO TRUJILLO, Profesora del Área de Entramados Comunitarios y Formas de lo Político, Posgrado de Sociología, Instituto de Ciencias Sociales y Humanidades, BUAP y co-coordinadora del Grupo de Trabajo de Ecologías Políticas de Abya Yala de CLACSO. Su principa línea de investigación es la ecología política y el feminismo. Correo electrónico: mlorena.navarrot@ gmail.com

Lucía LINSALATA, Profesora del Área de Entramados

Comunitarios

y Formas de lo Político, Posgrado de Sociología, Instituto de Ciencias Sociales y Humanidades, BUAP. Su principal línea de investigación es luchas comunitariospopulares en América Latina y formas de lo común. Correo electrónico: lucia. linsalata@gmail.com

Recibido: 30/09/2020 Aceptado: 10/1 I/2020

DOI:

https://doi.org// 0.15366/relacionesinternacionales2021.46.005

Formato de citación recomendado:

NAVARRO TRUJILLO, Mina Lorena y LINSALATA, Lucía (202I). "Capitaloceno, luchas por lo común y disputas por otros términos de interdependencia en el tejido de la vida. Reflexiones desde América Latina”, Relaciones Internacionales, $\mathrm{n}^{\circ}$ 46, pp. 8I-98. 
and non-human nature that violent accumulation logics constantly promote. This concern has led us to the task of endowing ourselves with an analytical, ecological, holistic and relational view of the notion of life, which we have been composing in dialogue with the ecology-world perspective, the Latin American political ecology tradition and some feminist traditions. In this article, based on diverse investigations in different countries of Latin America (Mexico, Bolivia, Ecuador, Guatemala, Colombia and Uruguay), we present what should be discussed when thinking about life, the Capitalocene and the struggles in defense of shared interests. The article consists of three sections. In the first, we explain what we mean by the condition of interdependence and how, from this idea, we recover the notion of "web of life" proposed by Jason W. Moore and other authors. We argue that life is a relational fact and that interdependence is an inescapable condition of all existence on planet earth. We only live thanks to the relationships of interdependence that we weave with other living beings and with the materiality that constitutes this extraordinary living being that we call Earth, capable of self-regulating through a series of complex cycles interdependent with each other. Recognizing this condition of coexistence implies, for us, assuming that life is as defined by Capra (1999), an immeasurably complex relational plot, a multidimensional network of relational networks interconnected with each other and immersed in a process of continuous evolution.

On the basis of those considerations, in the second section, we ask ourselves about the life that the modern-capitalist project has been reproducing from the logic of domination of an anthropocentric, patriarchal and colonial character, and the ways in which it has sought to reorganize the condition of interdependence; that is, putting human and non-human natures to work to ensure the logic of accumulation. We recover in this sense the idea of Capitalocene proposed by Moore (2020), in order to emphasize that the accumulation of capital is not a mere social process with environmental consequences; rather, it is a network of internal relations spanning the totality of the conformation of life. Therefore, it is also a way of continuously reorganizing the relations of interdependence in the web of life and historically linking human and extra-human natures to put them to work for the benefit of the generation of value. In recognizing the above, we also stress that the reorganization of the terms of interdependence posed by the processes of capitalist accumulation enters into a structural contradiction with the life cycles as a whole. This is because at the same time life reproduction patterns are imposed for the extraction and generation of value, necrotic metabolics (the exchange of matter and energy for the accumulation of capital, not for the reproduction of life) are also generated, which fractures and degrades the self-regulatory capacities of living organisms, of their environments and of the planet as a whole, alienating and reshaping the autopoietic powers inscribed in them. An example through which we illustrate the capitalist reorganization of the relationship of interdependence and its necrotic dynamics is the capitalist management of relations of interdependence around water in neoliberal times.

Lastly in the third section, we expose our approach to social antagonism and the struggles in Latin America for the common, to defend life and to manage the relations of interdependence in contradiction with the terms of capitalist co-production. First, we clarify what we understand by the production of the common good, and we maintain that this is sustained in specific modes of organization of relations of interdependence; that is, in the establishment of particular terms of relationship with the web of life that, in a situated way, guarantees the satisfactory reproduction of life within a specific community of people, and between it and the companion species and the natural elements that constitute their environment. Secondly, we propose, in dialogue with Marx, that the unlimited need to expand the frontiers of capital on the web of life systematically finds limits and resistances within the affected social networks. Even in those territories where lives have been repeatedly subsumed and reshaped by the logic of value, the renewed and violent imposition of new forms of dispossession may encounter resistances likely to trigger organizational processes of defense and re-appropriation of previously expropriated means of existence.This includes the production and/or regeneration of new commonalities and renewed forms of interdependence. In this sense, the social plots that produce the common are never something given or merely inherited, but are diverse and collective creations. This calls for repeated exercises aimed at disputing the terms of interdependence imposed by capitalist, patriarchal and colonial mediations, facilitating more satisfactory possibilities of organization and reproduction of life, both human and otherwise. We close the text by inviting readers to think how, in the midst of what the processes of multiple dispossession driven by capital have sought to deny, erode, fragment or alter, the defense and affirmation of life within such processes of struggle always supposes a practical and concrete exercise of regeneration and re-appropriation of political capacities. This highlights what is altered by the metabolism of capital and leads to a reaffirmation of other terms of interdependence.

Given the dark and uncertain times we are going through, the multiplicity of struggles in defense of life in Latin America invite us to look at and intervene politically, focused on the reproduction of life conforming to a need for regeneration from the capitalist, patriarchal and colonial damage inflicted on the web of life.

\section{KEYWORDS}

Interdependence; ecological world perspective; production of the common; struggles in defense of life; Latin America. 
En memoria de las mujeres y hombres asesinados por defender la vida en sus territorios en los últimos años en México y América Latina

\section{I}

\section{ntroducción}

Desde hace varios años, en el área de investigación de "entramados comunitarios y formas de lo político"' en la Universidad Autónoma de Puebla en México hemos venido estudiando, documentando $y$, en algunos casos acompañando, un amplio y variado abanico de procesos organizativos y luchas comunitarias en diferentes países de América Latina, en particular en México y Bolivia, pero también en Ecuador, Guatemala, Colombia y Uruguay. La mayoría de dichas luchas se han articulado en contra de los feroces procesos de despojo y explotación impulsados por la avanzada de los grandes capitales sobre los cuerpos-territorios ${ }^{2}$ del continente, para defender bienes comunes usufructuados y/o producidos colectivamente y evitar el colapso de las condiciones mínimas de reproducción de pueblos, barrios, familias y comunidades. Gran parte de la fuerza social desplegada a lo largo de tales procesos ha sido producida al interior de tramas organizativas de carácter comunitario y autogestivo que, si bien se presentan de forma singular y diversa en cada experiencia particular, suelen compartir rasgos similares y emparentados. Dos de ellos han sido, por un lado, la capacidad de defender las riquezas materiales y simbólicas producidas y/o usufructuadas en común frente a las lógicas de extracción de valor, reactualizando una multiplicidad de prácticas de producción de lo común profundamente difusas en el tejido social de cada uno de los países estudiados; y por el otro, la habilidad de producir e impulsar un sentido de disidencia común que ha puesto la defensa de la vida humana, y no sólo humana, en el centro del antagonismo social latinoamericano.

Nuestro caminar al lado de tales procesos, al igual que nuestro profundo compromiso con un horizonte político que pone la defensa y la reproducción de la vida en el centro de la lucha, nos ha llevado, en los últimos años, a hacernos dos preguntas que aquí compartimos. ¿Qué significa y qué implica defender la vida en medio de las renovadas dinámicas de despojo, devastación, degradación y reorganización de la vida misma, que las violentas lógicas de acumulación capitalista impulsan sin parar? ¿Qué se juega en aquellas luchas que, al tiempo de defender y producir un conjunto de bienes y ámbitos de vida comunes, están poniendo el horizonte político de la defensa de la vida en el centro de sus disputas?

\footnotetext{
El Seminario de Entramados Comunitarios y Formas de lo Político es una comunidad de trabajo coordinada por Raquel Gutiérrez, Mina Lorena Navarro y Lucia Linsalata que desarrolla sus actividades de investigación en el Programa de Posgrado de Sociología del Instituto de Ciencias Sociales y Humanidades “Alfonso Vélez Pliego" de la Benemérita Universidad Autónoma de Puebla (BUAP) en el centro de México. Desde 20I I, año de su creación por iniciativa de Raquel Gutiérrez, el seminario se ha convertido en un espacio de producción colectiva de pensamiento en el que estudiantes, intelectuales de México y otras partes del mundo, confluyen en la intención de generar un conocimiento situado y preocupado por entender la multiplicidad de formas políticas comunitarias que se practican y se producen desde el abajo del continente latinoamericano y reflexionar sobre las posibilidades de transformación social — pero, también, sobre los límites, las dificultades y las contradicciones- que se experimentan cotidianamente en tales realidades. Para más información, consultar: https:// horizontescomunitarios.wordpress.com/

2 En distintas latitudes de Abya Yala, desde el feminismo comunitario territorial y las mujeres que vienen enfrentando distintos procesos de extracción y expropiación de sus medios de existencia, hablan del cuerpo-territorio para reconocer el cuerpo propio, en conexión con el tejido de la vida y en interdependencia con el territorio que habitan (Cruz y Bayón, 2020). Desde este modo de ver, las mujeres no sólo han ido identificando los despojos, explotaciones y afectaciones al territorio- tierra del que son parte, sino también aquellas lógicas de dominio sobre sus propios cuerpos en su dimensión física, emocional y espiritual, encontrando que hay un continuum y nada está separado (Cabnal, 20I0). La defensa de la vida, experimentada desde el cuerpo, va reconociendo las batallas y las marcas en los cuerpos individuales y colectivos por el hecho colonial, patriarcal y capitalista, lo que se expresa en la consigna: "mi cuerpo como mi primer territorio de defensa", pero también luchando por cuidar, sanar, recuperar y reapropiarse del territorio cuerpo-tierra que históricamente se les ha querido despojar.
} 
Uno de los caminos que hemos transitado para vislumbrar algunas respuestas a estas inquietudes, ha sido el de ir componiendo una mirada analítica, ecológica, holística y relacional, en torno a la noción de vida. Dicha mirada, al tiempo de permitirnos visualizar la complejidad de las relaciones socioecológicas y de los procesos históricos de coproducción y mutua transformación que garantizan el sostenimiento y reproducción de la vida, nos ha posibilitado tomar distancia de los paradigmas cartesianos, atomísticos, mecanicistas y reduccionistas de comprensión de la misma y complejizar nuestra crítica tanto a las dinámicas capitalistas de reorganización violenta y continua del tejido de la vida en su conjunto, como a las relaciones jerárquicas - antropocéntricas, clasistas, patriarcales y coloniales - que las sostienen y posibilitan.

En este proceso de construcción colectiva, ha sido muy fértil para nosotras dialogar y aprender de la perspectiva de la ecología-mundo en su búsqueda por proponer lenguajes, métodos y estrategias narrativas acordes a una filosofía materialista, dialéctica y holística de la humanidad en la naturaleza y, desafiar los dualismos cartesianos y aquellas visiones filosóficas y analíticas del mundo que conceptualizan la naturaleza y la sociedad como separadas en términos ontológicos (Moore, 2020, p. 31 y 36). También nos hemos nutrido de la apuesta de diversas tradiciones del feminismo autónomo y marxista, el ecofeminismo, la economía feminista y la ecología política latinoamericana, por poner en el centro la condición de interdependencia y pensar desde la reproducción de la vida y con ello, hacer visibles la amplia galaxia de actividades y procesos materiales, emocionales y simbólicos que se realizan y despliegan en los ámbitos de actividad humana y no humana para garantizar la existencia (Federici, 20 I0; Mies, 20I 9; Pérez Orozco, 20I4; Machado, 2017).

En este texto presentamos algunas de las síntesis conceptuales que a partir de estos diálogos hemos producido en torno a la comprensión de la vida desde su condición de interdependencia, las dinámicas de apropiación, separación y mediación que los cambios metabólicos del capitalismo generan en el tejido de la vida y la disputa por los términos de la interdependencia que se expresa en el despliegue del antagonismo social de las luchas en defensa de la vida en América Latina.

\section{Hacia una comprensión interdependiente de la vida}

En diálogo con la economía feminista, partimos de un supuesto para nosotras fundamental. La reproducción de la vida humana - y no sólo humana - no puede ser pensada a partir de la fantasía moderna, antropocéntrica y androcéntrica, de la individualidad, que concibe al ser humano - y, en particular, al sujeto blanco, burgués, varón, adulto y heterosexual- como la medida y el centro de todo lo existente (Hernando, 2012; Pérez Orozco, 20I4; Navarro y Gutiérrez Aguilar, 2018). El mito del individuo racional y autosuficiente es una de las ideas más perversas y peligrosas del pensamiento moderno occidental. Su construcción se ha erigido sobre la negación de las complejas relaciones de interdependencia, cooperación y ayuda mutua que el ser humano teje con otros seres de su misma especie y de otras especies, y sobre la naturalización de las condiciones de desigualdad, explotación y dominio de la naturaleza, de las mujeres y de los pueblos colonizados, que el capitalismo ha generado (Mies, 2019).

Para alimentarnos, reproducirnos, desarrollar nuestras existencias y realizarnos como 
seres humanos, dependemos de otros seres, humanos y no humanos, así como de los elementos abióticos que constituyen nuestros ambientes. La vida toda se hace en interdependencia. Es ésta una condición ineludible de toda existencia en el planeta tierra y los seres humanos no representamos una excepción. En tal sentido, la idea cartesiana del "pienso, por tanto existo" ("cogito, ergo sum") es una vana ilusión. Sería mucho más sabio y realista, reemplazarla por otro enunciado en primera persona plural:“interdependemos, por tanto existimos” (Linsalata, 2020).

¿Cómo proponemos entender la condición de interdependencia? ¿Qué implicaciones tiene pensar la reproducción de la vida - humana y no humana - desde esta condición inscrita en el corazón de toda vida?

El famoso físico austriaco Fritjof Capra, quien ha dedicado buena parte de su labor teórica a la construcción de una comprensión sistémica de la vida y a la superación radical de toda visión cartesiana y mecanicista de la misma, nos brinda algunas pistas para aproximarnos a una respuesta. Al explicar la condición de interdependencia desde una perspectiva ecosistémica, escribe:

"Todos los miembros de una comunidad ecológica se hallan
interconectados en una vasta e intrincada red de relaciones, la
trama de la vida. Sus propiedades esenciales y, de hecho,sumisma
existencia se derivan de estas relaciones. El comportamiento
de cada miembro viviente dentro de un ecosistema depende
del comportamiento de muchos otros. [...] Comprender la
interdependencia ecológica significa comprender relaciones"
(Capra, 1999, pp. 196-197).

Vivir implica relacionarse. Sólo vivimos gracias a las relaciones de interdependencia que tejemos con otros seres vivos y con la materialidad toda que constituye este extraordinario ser vivo al que llamamos Tierra, capaz de autorregularse mediante una serie de complejos ciclos interdependientes entre sí, tal y como se afirma en la hipótesis Gaia formulada por James Lovelock y Lynn Margulis (2018). Reconocer esta condición de coexistencia implica asumir que la vida en este planeta es mucho más que la suma de todas las partes que la integran. Las relaciones socioecológicas de interdependencia que sostienen y posibilitan la reproducción de la vida, tanto humana como no humana, son heterogéneas, articuladas, variables, contingentes, históricas, multiescalares; suponen bucles constantes de retroalimentación y dinámicas complejas de asociación, cooperación y coevolución, tanto entre organismos vivos, como entre éstos y el entorno abiótico que habitan. La vida, tal como la definió Capra (1999), es una trama relacional inconmensurablemente compleja:"una red multidimensional de redes relacionales interconectadas entre sí e inmersas en un proceso autopoiético en continuo devenir, marcado por el fluir incesante de materia y energía a través de los organismos vivos y sus entornos” (Linsalata, 2020).

En sintonía con esta mirada, se encuentra el fascinante trabajo de la bióloga Lynn Margulis (2002) para sustentar la mencionada hipótesis Gaia y la teoría de la endosimbiosis con la que ha demostrado que la vida en la Tierra es simbiótica, en la que miembros de diferentes especies viven en contacto físico y a partir de esas relaciones se crea novedad, garantizando el cambio evolutivo 
y el surgimiento de nuevas especies. ${ }^{3}$ Entre esas especies simbióticas o animales simbiontes nos encontramos los seres humanos que, para subsistir interdependemos con los mundos microbianos que habitan en nosotros para hacer posible nuestras actividades más vitales (pp. I5-22).

En tal sentido, recuperar la metáfora de la vida como tejido o trama - ya propuesta por otros autores (Capra, 1999; Moore, 2020) — implica para nosotras dar cuenta de la vida como un flujo de relaciones y reconocer el valor intrínseco de todas las especies compañeras ${ }^{4}$ (Haraway, 2016) que la conforman, así como señalar que la vida no es algo dado, sino algo que se va construyendo como resultado de las interrelaciones y las interacciones entre diversas especies.

Por ello, coincidimos plenamente con Horacio Machado, cuando nos recuerda que no existen fracturas ontológicas entre lo humano y lo no humano, "sino apenas membranas porosas por donde fluyen materia y energía, por donde fluye la vida en sí, como trama, en la que los humanos actuamos y somos a través del mundo, así como el mundo se mueve y es también a través de nuestros organismos" (2020).

Ahora bien, la civilización capitalista se ha erigido sobre la negación de las complejas relaciones de interdependencia que permiten a la vida tejerse. Desde sus orígenes, la modernidad capitalista, o como diría Bolívar Echeverría (1989) la modernidad realmente existente, se presentó como un proyecto emancipador, fundador de un Nuevo Mundo, cuyo protagonista principal sería el individuo racional, concebido como un ser totalmente independiente de la llamada Naturaleza, capaz, no sólo de emanciparse de ella, sino también de dirigirla y dominarla a través de la ciencia y la racionalidad instrumental. Este individuo, racional y moderno, se coloca frente a todo aquello asociado a la noción homogeneizante de Naturaleza, desde una postura de exterioridad, que niega los fundamentos históricos y materiales de su existencia, estableciendo una relación de superioridad y dominio respecto a los otros seres vivos (Machado, 2019).

Con relación a este punto, en el marco de la perspectiva de la ecología-mundo, Jason W. Moore hace una útil distinción entre Naturaleza con $\mathrm{N}$ mayúscula y $n$ minúscula. La Naturaleza con $\mathrm{N}$ mayúscula - es, para Moore, una producción histórica del pensamiento moderno occidental y se concibe como una entidad externa, susceptible de ser codificada, controlable, cuantificada y racionalizada, al servicio del crecimiento económico, del desarrollo social o algún otro bien mayor. En ese sentido, los múltiples proyectos del capital han estado orientados a producir una Naturaleza, mientras que el tejido de la vida es la naturaleza en su integridad: naturaleza con una empática $n$ minúscula (Moore, 2020, p. I7) —y agregaríamos - en plural, tal y como el geógrafo Erik Swyngendouw propone al recordarnos que "no existe una Naturaleza singular (...) sino, por el contrario, un abanico de diferentes naturalezas históricas, relaciones y medio ambientes sujetos a cambios y transformaciones continuos" (20II, p. 45).

En la visión cartesiana del mundo, no hay imagen mejor que sintetice la concepción de la Naturaleza y el individuo moderno que la separación entre res cogitans y res extensa propuesta

\footnotetext{
3 En sus investigaciones logra demostrar cómo la simbiosis de larga duración condujo primero a la evolución de células complejas con núcleo y a partir de ahí a otros organismos, como los hongos, las plantas y los animales (Margulis, 2002, p. 16).

4 Con esta noción Donna Haraway (20l6), incluye a seres orgánicos tales como el arroz, las abejas, los tulipanes y la flora intestinal, es decir, a todos los seres que hacen de la vida humana lo que es y viceversa.
} 
por Rene Descartes en el siglo XVII. Escisión según la cual todo aquello que corresponde a la res extensa, incluido el mismo cuerpo humano, es convertido en un mecanismo inerte sin agencia (Apffeel-Marglin, 20I8) que responde a las leyes fisicoquímicas de la Naturaleza y que, por tanto, es susceptible de ser estudiado, diseccionado, controlado y finalmente conquistado por las inmensas capacidades racionales del ser humano. Sin embargo, cabe reconocer que dichas capacidades no han sido históricamente un "derecho" concedido a toda la humanidad, a todos los pueblos o a todos los géneros. Por siglos, el estatus de individuo racional ha sido un privilegio otorgado sólo a los que María Mies llama “los modernos patriarcas capitalistas”, una minoría de varones, blancos y propietarios, quienes se otorgaron en nombre de la Razón, el derecho de establecer su dominio sobre todo aquello que en su visión del mundo quedaba asociado a lo natural o al estado de naturaleza (2019).

En relación con esto, Horacio Machado (2020) llama la atención sobre el carácter profundamente imperial de la Razón moderna capitalista y de la figura de hombre que la encarna: el hombre conquistador que se concibe a sí mismo como individuo que prescinde de todo y se arroga el señorío del mundo, tratando a la tierra y a los cuerpos racializados, feminizados y subalternizados de su misma especie como objetos de dominio y explotación.

¿Qué vida ha sido la vida que el proyecto moderno-capitalista ha ido produciendo a partir de esta lógica de dominio de carácter profundamente antropocéntrica, patriarcal y colonial? ¿De qué manera el capitalismo ha organizado el tejido de la vida y las relaciones de interdependencia que la sostienen? A continuación, esbozamos el camino que hemos ido transitando para contestarnos estas preguntas.

\section{El capital en el tejido de la vida}

En el recorrido para entender cómo el capitalismo y su lógica patriarcal y colonial ha ido fracturando y transformando el tejido de naturalezas humanas y no humanas, así como de los elementos abióticos que constituyen nuestros ambientes, hemos entrado en diálogo con la perspectiva de la ecología-mundo y los aportes de su precursor Jason W. Moore, para poner en juego una visión poscartesiana y abonar en una comprensión histórica de las relaciones entre el capitalismo, la naturaleza y el poder. En este esfuerzo, reconocemos la búsqueda por reconceptualizar la historia ambiental rastreando las coproducciones que desde el siglo XVI, en el marco del Capitaloceno, se han desplegado en los nuevos patrones de configuración de la humanidad en la naturaleza y de la naturaleza en la humanidad (Moore, 2020, pp. I7- I8; y Navarro y Machado, 2020).

Cuando hablamos del Capitaloceno asumimos una distancia crítica de los diagnósticos que señalan que el origen de la crisis socioecológica actual es antropogénica, al asumir que lo humano es un todo homogéneo, como unidad ficticia en la que se desdibujan las responsabilidades particulares y las formas concretas de intervención, apropiación y coproducción en el tejido de la vida. Las narrativas dominantes del Antropoceno sacan de la ecuación al capitalismo y omiten su responsabilidad en marcar las pautas destructivas de las transformaciones ecosistémicas y termodinámicas en el planeta (Wedekind y Milanez, 2017; Moore, 2020; Navarro, 2020a). En pocas palabras, coincidimos en que el problema no es el Antropos en general, sino las relaciones del 
capital y el patrón de configuración ambiental que desde el siglo XVI ha privilegiado la acumulación sin fin (Moore, 2020, p. 205).

Desde esta perspectiva, el capitalismo no es una producción exterior al tejido de la vida, un sistema económico o un sistema social como generalmente se le concibe, sino una "forma de organizar las naturalezas y de organizarnos nosotros en ellas y a través de ellas" (Moore, 2020, Pp. 17 y 20). Tal como nos explica Moore, el capitalismo es una coproducción de proyectos y procesos que parten de la iniciativa humana y se articulan, a través de relaciones asimétricas de apropiación y explotación, con y dentro de otras naturalezas específicas (p. 35). De modo que la acumulación del capital no es un mero proceso social con consecuencias medioambientales, sino una red de relaciones internas a la totalidad de la conformación de la vida (Navarro y Machado, 2020) y en ese sentido, una ecología-mundo, es decir, una forma de enlazar las naturalezas humanas y extrahumanas para ponerlas a trabajar en beneficio de la generación de valor (Navarro y Machado, 2020).

Este entendimiento de la coproducción entre capitalismo y naturalezas nos ha llevado a reconocer dos cuestiones. Por un lado, nos ha permitido visualizar la enorme capacidad necrótica ${ }^{5}$ de la acumulación del capital a lo largo de la historia, es decir, la acción sistemática de transformar ambientes, degradar los sistemas vivos y las capacidades de autorregulación y de complejización que ha permitido la evolución creativa y diversa del planeta (Navarro y Gutiérrez Aguilar, 20 I8), así como las condiciones que posibilitan la regeneración y reproducción de la vida a través de la violencia y la muerte impuesta. ${ }^{6}$ Por otro lado, nos ha llevado a ahondar críticamente en la ficción de la omnipotencia y omnipresencia con la que el capital presume absoluta capacidad de control y subordinación de los procesos vitales. ${ }^{7}$ En pocas palabras, sin desconocer la capacidad destructiva del capital, nos proponemos reconocer su fragilidad en el intento por organizar el tejido de la vida a su imagen y semejanza.

¿Por qué afirmamos lo anterior? ¿Qué implica organizar en términos capitalistas las naturalezas o el tejido de la vida? ¿Cuáles son los desafíos de la empresa capitalista para lograrlo?

Para encarar estas preguntas, hemos aprendido de la mano de fértiles discusiones del eco-marxismo que la coproducción capitalista de las naturalezas ha ido generando, lo que Jason W. Moore ha denominado como cambios metabólicos (Moore, 2020, p. 105-107), que en nuestras palabras podemos definir como la generación de sucesivas alteraciones en los flujos y patrones de intercambio de materia y energía de los sistemas vivos y, por tanto, de los términos en los que se organizan las relaciones de interdependencia inter e intra especie (Navarro y Gutiérrez Aguilar, 2018, p. 50). Estos cambios incluyen tanto la fractura del metabolismo anterior (Foster, 2000) a partir de imponer separaciones en el tejido de la vida, así como la simultánea generación

\footnotetext{
Recuperamos el trabajo de Vanesa Carsolio (2020) sobre la coproducción especista en el Capitaloceno y su diálogo con Mc Brien (20I6) en torno a la noción de necrotización.

6 Recuperamos la gramática de la Agrupación Un Salto de Vida quienes hablan de muerte impuesta para referirse a la muerte que no es elegida ni es natural, sino que forma parte de procesos de despojo y violencia del capital.Al respecto, Enrique Enciso, uno de sus integrantes, comenta: "Ahora estamos aquí, ya no trabajamos en las empresas, no tenemos los dineros, no tenemos seguridad vital, no tenemos libertad.Y ahora en este momento ya estamos como en un punto que estamos a punto de ser leña, con una muerte que no hemos elegido, nos la han impuesto los cabrones" (Navarro, 2020b).

Las luchas en defensa de la vida y otras formas del antagonismo social históricamente han fungido como una fuerza corrosiva de la arrogancia con la que el capital invisibiliza su carácter dependiente de la actividad humana y en general del tejido de la vida.
} 
e imposición de un patrón de reconexión sostenido por mediaciones y ensambles funcionales a la valorización del valor, tales como el salario, el mercado, la familia heteropatriarcal, el Estado, etc. (Navarro y Gutiérrez, 20I8, p. 50).

Cuando hablamos de separación nos referimos a la fractura y cambio de las relaciones de hombres y mujeres con sus medios de existencia, dinámica que se presenta desde la llamada acumulación originaria, como momento histórico en los albores del capitalismo que Marx documentó ampliamente para el caso de Inglaterra (Marx, 1975 [1867]). No obstante, cómo lo han advertido una serie de voces del marxismo crítico, como la de María Mies (2019), Silvia Federici (2010), Massimo de Angelis (2012), George Caffentzis (1995), entre otros, es también una lógica continua y necesaria en la generación de valor que persiste hasta nuestros días.

En diálogo con Jason W. Moore, diríamos que estos procesos de separación con sus respectivos cambios metabólicos se acentúan con la expansión y ampliación histórica de las fronteras capitalistas de las zonas de apropiación de Naturalezas Baratas, adecuando el trabajo no remunerado al servicio de la producción mercantil. En tal sentido, la perspectiva de Moore se diferencia enormemente de la teoría marxista clásica y aquella comprensión que sitúa la principal contradicción del capital con el trabajo humano asalariado en el terreno de la relación de explotación y enajenación. Contrariamente a esta postura, Moore - al igual que varias pensadoras feministas marxistas como Leopoldina Fortunati, Maria Rosa Dalla Costa y Silvia Federici- nos abre una ventana para ver cómo la producción de valor no se basa sólo en la explotación del trabajo humano asalariado, sino también en la apropiación de inmensas cantidades de trabajo/energía no remunerado (humano y no humano) por afuera de los circuitos clásicos de la producción capitalista; es decir, que la generación de valor capitalista es posible sólo a partir de procesos simultáneos de explotación de trabajo remunerado y apropiación de trabajo/energía no remunerado (2020, p. 227) . Tal trabajo no remunerado es llevado a cabo "por seres humanos - mujeres y esclavos, por ejemplo- o por naturalezas extrahumanas, como bosques, suelos o ríos" y representa la base material a partir de la cual el capital expande continuamente sus fronteras sobre el tejido de la vida, reorganizando las dinámicas de reproducción de la misma de acuerdo con la lógica de la ganancia sin fin. Desde los orígenes del Capitaloceno, dichos movimientos de fronteras han sido esenciales para la creación de formas de Naturaleza Barata necesarias para el capitalismo, a través de los Cuatro Baratos: trabajo, alimentos, energía y materias primas (Navarro y Machado, 2020).

En esta ampliación de fronteras de nuevas zonas de apropiación, los procesos de separación se garantizan a partir de fijar mediaciones que van transformando de manera radical las naturalezas y los términos en los que se organizan las relaciones de interdependencia, estableciendo formas de explotación y enajenación de los medios de existencia funcionales a la acumulación de capitales. Así, la coproducción histórica de modos de existencia capitalistas se sostiene en un metabolismo que reorganiza el tejido de la vida para extraer y exprimir el mayor valor posible, gestionando la interdependencia en términos de explotación (Pérez Orozco, 2014, p. 53), es decir, poniendo en el centro su lógica de acumulación de ganancias y no la de la reproducción de la vida (Navarro y Gutiérrez Aguilar, 2018).

Este violento proceso, al que llamamos "reorganización capitalista de la condición de interdependencia" (Linsalata, 2020, p. 55), se constata en la imposición de patrones de relación 
e intercambio de materia y energía, y en general de organización de la vida, que en términos estrictamente bio-geoecológicos generan bucles de retroalimentación necróticos. De modo que, la reorganización de los términos de interdependencia planteados por los procesos de acumulación capitalista entra en una contradicción estructural con los ciclos vitales en su conjunto, puesto que, al tiempo que se imponen unos patrones de reproducción de la vida para la extracción y generación de valor, también se van fracturando y degradando las capacidades autoregulativas de los organismos vivos, de sus entornos y del planeta en su conjunto, enajenando y refuncionalizando las potencias autopoiéticas inscritas en los mismos (Linsalata, 2020, p. 56).

En resumen, son al menos tres dinámicas las que coexisten en la reorganización capitalista de la condición de interdependencia (Linsalata, 2020, p. 56):

I. La instauración y reiteración constante (bajo formas históricamente renovadas y geográficamente diferenciadas) de la separación simbólica y material de hombres y mujeres de nuestros medios de existencia, y la consecuente fractura y cambio metabólico de relaciones sociales, biológicas y ecológicas correspondientes a formas sociales anteriores.

2. La reconexión y reorganización de lo inicialmente separado, bajo los términos fijados por las mediaciones capitalistas, patriarcales y coloniales (el estado, el derecho, el mercado, el salario, la familia heteropatriarcal, etc.) y las escalas espaciotemporales funcionales a la reproducción ampliada del valor.

3. La conversión de nuestros medios de existencia, incluido nuestro cuerpo y nuestra capacidad viva de trabajo, en cosas explotables y valores independientes y aparentemente ajenos a nosotros, cuya posibilidad de acceso y usufructo queda paulatinamente limitada y/o gestionada por las mediaciones capitalistas, patriarcales y coloniales previamente fijadas.

Un ejemplo nos ayudará a visualizar mejor la complejidad de las dinámicas que estamos tratando de presentar. Pensemos por un instante en la forma en que desde el capital se han ido gestionando y organizando las relaciones de interdependencia en torno a un bien tan esencial para la reproducción de todas las vidas como es el agua. No nos será difícil reconocer que el agua, al igual que muchos otros elementos de los entornos bióticos y abióticos que habitamos, ha sido reducida por la cultura moderno capitalista a una simple cosa que puede ser separada de las relaciones de interdependencia que sostiene y que la retroalimentan, para ser convertida en una mercancía, en un recurso apropiable, dominable, cosificable, controlable y contaminable por el ser humano y administrable a través de la mediación del mercado y el dinero.

Un ejemplo muy claro de lo anterior es la tragedia que muchos países del planeta han experimentado en relación con la mercantilización y privatización del agua de uso domiciliario durante la época neoliberal; tragedia que nos ha llevado a un contexto como el actual, en el que 3 de cada 10 personas o más de 2, 100 millones de personas carecen de agua potable en el hogar y más del doble no disponen de saneamiento seguro en todo el planeta (OMS, 20 I7). Bajo el argumento de la presunta ineficiencia de los sistemas públicos y de los sistemas cooperativos/comunitarios y la supuesta eficacia y capacidad financiera del sector privado, durante varias décadas se ha procedido al paulatino desmantelamiento tanto de los servicios públicos como de una infinidad 
de experiencias cooperativas y/o comunitarias de gestión del agua, para dar paso a la privatización de dicho servicio en manos de empresas privadas y grandes corporaciones trasnacionales (Batista Medina, 2014, p. 163). Uno de los aspectos más lamentables de lo anterior ha sido la dilución de una multiplicidad de relaciones de interdependencia y formas de organización social en torno al agua, dentro de las formas de relacionamiento homogéneas, enajenadas e individualizadas que nos impone el mercado, al interior de las cuales la mayoría terminamos siendo reducidos a simples consumidores que pagan mensualmente por la cantidad de agua proporcionada por la empresa privada en turno. Agua de la que desconocemos sus orígenes, sus caminos, que se transforma en cada vez más lugares del planeta en un agua desterritorializada, despojada de sus trayectorias atmosféricas, superficiales y subterráneas y, "liberada" de sus vínculos ecológicos, espaciales y bioculturales.

La mercantilización y, por lo tanto, la fijación de la mediación dineraria en el metabolismo capitalista del agua — sus fuentes, redes de suministro y servicios de abastecimiento-, ocultan las múltiples formas de despojo, dominación y explotación que alimentan la maquinaria del sistema hídrico, permitiendo que se lleve a cabo, una y otra vez, una profunda desconexión de las naturalezas transformadas de su fundamento biogeoquímico y sociocultural. Es así como a partir de grandes obras hidráulicas y sofisticadas tecnologías, este precioso líquido es puesto a circular en función de los ritmos, de las necesidades económicas, de las condiciones de existencia y de las escalas espaciales impuestas por los procesos de acumulación de capital, imponiendo metabolismos socio-ecológicos profundamente desequilibrados. Trasladada de un lugar a otro, el agua puesta "al servicio del capital", encuentra su uso en lugares cada vez más distantes de las fuentes de origen, en detrimento de sus ciclos naturales, de los vínculos con el sistema de cuenca, con las comunidades concretas de vida y con las relaciones históricas y culturales que solían definirla en cada lugar de forma diferente.

De este modo, el sistema de percepciones y las relaciones simbólico-afectivas que como sociedades humanas hemos ido tejiendo históricamente en torno a este líquido, así como las formas tradicionales de gestión y relacionamiento colectivo con el agua, se fragmentan, para terminar diluidas en un acto de consumo homogéneo, mercantilizado, enajenado, individualizado y automatizado, que se celebra cotidianamente bajo los términos y las mediaciones impuestas por el capital. En suma, hablamos de profundas fracturas y cambios metabólicos de los ciclos naturales del agua y los términos de interdependencia tejidos colectivamente desde la garantía de la reproducción de la vida para imponer patrones de reconexión sostenidos por mediaciones y ensambles funcionales a la valorización del valor.

El capital impone sus prioridades, sus jerarquías y modalidades de uso, a costa de la vida y el bienestar de extensos territorios y millones de seres vivos y especies compañeras. Y al hacerlo promueve una separación ontológica que alienta narrativas históricas e imaginarios sociales en las que las relaciones entre seres humanos se presentan como independientes del resto de la naturaleza (Moore, 2020, p. 37). Es así como miles de millones de hombres y mujeres en el mundo tienen profundamente interiorizada una visión cosificada del agua y se relacionan diariamente con ésta a partir de un sentimiento de desafección que les impide percibir y/o sentirse afectados por todo lo que acabamos de mencionar. Sin embargo, también es cierto que millones de entramados comunitarios en todo el planeta luchan, y lo seguirán haciendo, por no perder sus culturas del agua 
y/o por crear nuevas; por desalienar y defender sus fuentes de agua, y con ellas, sus territorios y una multiplicidad de formas concretas de vida; por tener un acceso más igualitario a este líquido y por producir otras formas de gestión colectiva del mismo, más dignas para ellos y más respetuosas de los entornos vivos que habitan.

Tal y como hemos señalado anteriormente, la empresa capitalista de coproducción -en y a través del tejido de la vida - de naturalezas funcionales a la acumulación de valor no logra nunca de manera plena su cometido, es decir, los cambios metabólicos o alteraciones de los términos de la interdependencia que los patrones de vida capitalista nos imponen, tienen siempre como correlato el despliegue de conflictos, luchas y antagonismos. A cada avance del capital, se abren nuevas disputas protagonizadas por variados sujetos colectivos y formas políticas que buscan acortar las distancias generadas por los procesos capitalistas de separación y establecer un patrón de relación e intercambio específico de materia y energía acorde con la reproducción de la vida y con lo necesario para garantizar sus modos de existencia.

En lo que sigue, presentaremos de manera sintética nuestra comprensión de las múltiples y diversas luchas comunitarias y colectivas que buscan organizar sus relaciones de interdependencia en antagonismo con los proyectos sistemáticos de reorganización capitalista del tejido de la vida.

\section{Leer las luchas en defensa de lo común y de la vida desde la clave de la interdependencia}

El seguimiento y compromiso con la variopinta y polimorfa manera en que diversos colectivos humanos, en distintas latitudes de América Latina, se empeñan en luchar de manera cotidiana y extraordinaria para garantizar las condiciones materiales y simbólicas de su propia (re)producción, nos fue llevando a preguntarnos insistentemente: ¿Cómo se sostienen las luchas en defensa de la vida? ¿Cuáles son sus condiciones de posibilidad? ¿Cuáles son las formas cotidianas de su lucha? ¿Cómo sostienen la reproducción de sus vidas quienes luchan por su defensa?

Estas preguntas nos han ayudado a reconocer la centralidad que suelen adquirir, al interior de muchos de estos procesos de lucha y de las actividades organizativas y reproductivas que los sostienen, un conjunto de prácticas políticas de carácter comunitario y colectivo que, si bien se presentan de forma singular y diversa en cada experiencia particular, suelen compartir rasgos similares y emparentados. Hemos llamado a este hacer político: producción de lo común y lo hemos descrito como una actividad práctica que se establece entre un conjunto de personas capaces de entrelazar sus haceres y establecer vínculos de cooperación para solucionar problemas y necesidades compartidas. En consonancia con ello, en diversos textos, hemos subrayado que cuando hablamos de producción de lo común hablamos antes que nada de una relación social, o mejor dicho, de la capacidad social de tejer tramas relacionales de asociación y cooperación dirigidas a habilitar cotidianamente la producción y el disfrute colectivo de una gran cantidad de valores de uso, esto es, de bienes materiales y simbólicos de uso común destinados a la reproducción satisfactoria de la vida (Federici y Caffentzis, 2019; Gutiérrez Aguilar, 2017; Gutiérrez Aguilar, Navarro, y Linsalata, 20 I7; Gutiérrez Aguilar y Navarro, 2019; Linsalata, 2019). ${ }^{8}$

8 A este respecto, recomendamos revisar los distintos números de la Revista de Estudios Comunitarios El Apantle y la más reciente compilación 
Las luchas en defensa de la vida son procesos que, al tiempo de defender un conjunto de ámbitos materiales y simbólicos, producen constantemente lo común en la medida en que se empecinan en reafirmar —en contra de los procesos de apropiación, separación y mediación impuestos por la violencia capitalista - la capacidad social de (re)apropiarse de las riquezas disponibles y/o generadas colectivamente y de (re)generar los vínculos sociales, afectivos y ecológicos que permiten producir conjuntamente decisiones sobre su gestión y usufructo.

A partir de diversas investigaciones, fuimos encontrando al menos dos rasgos comunes en las experiencias de lucha en defensa de la vida: I) la centralidad de la garantía de la reproducción material y simbólica de la vida colectiva y las multiformes prácticas comunitarias que la regulan y sostienen en medio de los continuos procesos de despojo y desgarramiento del tejido social impuestos por las dinámicas capitalistas; 2) la capacidad política de producir continuamente vínculos sociales y afectivos, así como un conjunto de creaciones materiales y simbólicas, que se comparten, gestionan y producen colectivamente a través de lógicas organizativas que fisuran, diluyen - y en muchos casos, desbordan — las mediaciones impuestas por la lógica del valor.

Lo anterior lo hemos visto en una diversidad de experiencias comunitarias y colectivas que buscan el fortalecimiento de las instituciones comunitarias y las formas de autogobierno en medio de amenazas territoriales; la reconstrucción del tejido social cuando la fragmentación se hace presente en contextos de guerra o desastre; la profundización del vínculo con la tierra a partir de la puesta en marcha de proyectos productivos y agroecológicos que fortalecen la autonomía material; la gestión comunitaria y colectiva de sistemas de agua en contextos rurales y urbanos; el reconocimiento, resguardo y regeneración de la biodiversidad a través del diseño e implementación de reglamentos internos para la protección del territorio, como es el caso de las declaratorias ambientales y de territorios prohibidos y libres de minería; la recuperación y reafirmación de la ancestralidad y la espiritualidad; el trabajo colectivo de mujeres para nombrar las relaciones de violencia al interior de los espacios de vida que habitan y producir justicia comunitaria.

Ahora bien, a partir de todo lo que hemos dicho anteriormente, nos parece importante reconocer y subrayar que la producción de lo común por parte de cualquier entramado colectivo es a la vez un modo específico de gestión y organización de sus relaciones de interdependencia en el tejido de la vida del que es parte. Esto parece obvio, pero no lo es cuando nos damos cuenta de la gran eficacia de la articulación histórico-funcional entre el Estado, la Ciencia y el Capital para conformar un poderoso aparato semiótico-político de producción de la realidad (Machado, 20I4, p. 10) con el que percibimos lo humano como entidad separada de las complejas relaciones de interdependencia con otros seres humanos y especies compañeras.

Por ello no nos parece banal reafirmar que la producción de lo común se sostiene en modos específicos de organización de las relaciones de interdependencia, es decir, en el establecimiento de unos términos particulares de relacionamiento con el tejido de la vida que, de manera situada, garantizan la reproducción satisfactoria de la vida al interior de una comunidad concreta de personas y entre ésta y las especies compañeras y los elementos naturales que constituyen su

de Producir lo común. Entramados comunitarios y luchas por la vida a cargo de Traficantes de Sueños (20।9). 
entorno. Pero ¿cómo se afirma la vida y posibilita la producción de lo común cuando las lógicas del capital han fracturado los patrones previos de reproducción e impuesto mediaciones y dinámicas funcionales a la lógica del valor, explotando las fuerzas vitales y expropiando las capacidades políticas de decisión?

Para contestar esta pregunta, nos hemos propuesto seguir con especial atención los modos en los que el antagonismo social, de diversas maneras, se despliega en el tejido de la vida exhibiendo las contradicciones de los modos de existencia en el Capitaloceno. En diálogo con Marx, no hemos dejado de reconocer el carácter antagónico y conflictivo de los procesos de apropiación, separación y mediación a través de los cuales el metabolismo necrótico ${ }^{9}$ del capital se coproduce en el tejido de la vida. Como ya hemos señalado, la ilimitada necesidad de expandir las fronteras del capital y, con ella, la producción y reproducción ampliada de nuevas separaciones en el tejido de la vida encuentra sistemáticamente límites y resistencias al interior de las tramas sociales afectadas. Aún en aquellos territorios cuyas vidas han buscado ser reiteradamente subsumidas y refuncionalizadas por las lógicas del valor, la imposición renovada y violenta de nuevas separaciones encuentra resistencias susceptibles de detonar procesos organizativos de defensa y reapropiación de los medios de existencia previamente expropiados y, con ello, de producción y/o regeneración de nuevos comunes y formas renovadas de interdependencia. En tal sentido, las tramas sociales que producen común "nunca son algo dado o meramente heredado, sino que son creaciones colectivas plásticas y diversas” (Gutiérrez Aguilar y Navarro, 2019, p. 319): ejercicios reiterados dirigidos a disputar en contra y en medio de los términos de interdependencia impuestos por las mediaciones capitalistas, patriarcales y coloniales, posibilidades más satisfactorias de organización y reproducción de la vida, humana y no sólo humana.

Para ejemplificar lo anterior, retomamos sucintamente lo que hemos aprendido de diversas luchas por lo común en contextos de conflictividad socioambiental, con el fin de hacer notar los modos en los que se expresa la contradicción que genera el metabolismo del capital en el tejido de la vida, así como el antagonismo social que se despliega para defender los medios de existencia y confrontar la extracción de valor a partir del desarrollo de toda clase de proyectos (Composto y Navarro 2014; Navarro, 20 I5; Linsalata, 2016; y Rátiva, 2019).

En diversas comunidades indígenas y campesinas, aunque no únicamente, hemos visto que el asedio y afectación de los proyectos extractivos en los cuerpos-territorios cifrados como zonas de sacrificio, abre un tiempo extraordinario y con ello, la emergencia de un sentido colectivo de afectación y de enlace cooperativo. Los sujetos colectivos van produciendo una serie de determinaciones para garantizar la defensa y resguardo de sus medios de vida, a partir de combinar creativamente múltiples frentes organizativos, como es el trabajo de base, la acción directa, la resistencia civil, la defensa jurídica, la exigencia activa ante gobiernos y empresas y, la articulación y generación de alianzas con otros actores en distintas escalas.

Es éste el caso, por ejemplo, de los procesos organizativos que hemos visto emerger en la Sierra Norte de Puebla en México a raíz de la emergencia de múltiples proyectos extractivos

\footnotetext{
Retomamos el planteamiento de Horacio Machado sobre la (necro)economía del capital o el metabolismo necroeconómico del capital, quien alude, "en sentido inverso, al de bio-economía elaborado por Georgescu-Roegen (1996), procurando explicitar el antagonismo radical que entendemos existe entre la economía de la naturaleza y la economía del capital (Machado, 2012 y 20I6).
} 
(mineros, hidroeléctricos, hidrocarburíferos y turísticos) que amenazan con trastocar las complejas relaciones socio-ecológicas de reproducción de la vida en la región. A medida que las amenazas sobre este territorio se hicieron manifiestas, las comunidades de la Sierra poblana fueron comprendiendo los riesgos que tales proyectos implican para el articulado sistemas de cuencas hidrográficas que sostienen los metabolismos de la región y el bienestar de los ecosistemas de los que dependen las comunidades campesinas de este territorio. Fue así que, a partir de la comprensión de las relaciones de interdependencias que se tejen en torno a las cuencas y a los acuíferos de la región, en la multiplicidad de asambleas locales y regionales que se fueron conformando ante las amenazas, se fue extendiendo la idea de que, independientemente de las distancias, toda la Sierra Norte de Puebla era un territorio común, interdependiente y fuertemente interrelacionado por los flujos de agua que lo recorren y tejen. Por lo mismo, los proyectos de muerte representaban una amenaza común y la lucha contra los mismos debía ser enfrentada conjuntamente.

El reconocimiento colectivo de las tramas socioecológicas de interdependencia que se tejen en torno a y a través de los flujos del agua impulsó un admirable proceso de articulación y colaboración entre pueblos, cuya expresión más visible es, sin duda, la Asamblea de los Pueblos Maseual, Totonaku y Mestizo en Defensa de la Vida y el Territorio. Se trata de un proceso regional en donde periódicamente se reúnen miles de personas pertenecientes a cientos de comunidades y decenas de municipios de toda la Sierra Norte poblana, así como de regiones aledañas de otras entidades federativas (Hernández Hernández, 2019; Linsalata, 20I7); una asamblea territorial desde la cual se ha podido echar a andar una multiplicidad de acciones colectivas, desde la interposición de procesos de amparo para la defensa del territorio hasta la organización de marchas y plantones de protesta o de acciones dirigidas a la vigilancia ambiental y al saneamiento del territorio.

Cabe destacar que, en procesos de este tipo, la producción de lo común se expresa en la persistente disputa por conservar y garantizar los ámbitos que garantizan la vida ante las dinámicas de despojo, expropiación y explotación; pero también por tratar de recuperar el control y acceso de los medios de existencia que han sido expropiados, contaminados y degradados a partir de las transformaciones metabólicas y la fijación de mediaciones capitalistas.

En medio de aquello que las separaciones y los procesos de despojo múltiple han buscado negar, erosionar, fragmentar o alterar, la producción de lo común es un ejercicio de conservación de lo que se tiene, pero también de reconexión y reapropiación de lo perdido o alterado por el metabolismo del capital y de regeneración de los vínculos de interdependencia. En ese sentido, la defensa y afirmación de la vida supone siempre un ejercicio práctico y concreto de autodeterminación y gestión de las relaciones de interdependencia que se desean construir.

Una de las preguntas que se escucha y resuena en muchos de los territorios en los que se viene imponiendo la lógica sacrificial de la acumulación de capital, a través de la expansión de zonas de apropiación es ¿cómo generar procesos de reapropiación comunitaria de modos y medios de vida que se hagan cargo de la regeneración parcial de los daños capitalistas, patriarcales y coloniales en el tejido de la vida? Sin duda, las luchas en defensa de la vida están generando un saber-hacer crucial y estratégico en esta encrucijada civilizatoria. 


\section{A manera de conclusión}

Los tiempos críticos que enfrentamos, nos colocan ante el desafío ya impostergable de fisurar las abstracciones de la visión cartesiana de la modernidad capitalista, revisando, abriendo y experimentando nuevas nociones, lenguajes, comprensiones y narrativas de la vida en su dimensión histórica, relacional, interdependiente, ecológica, contingente e inconmensurable. En este texto nos propusimos avanzar en esa dirección a partir de compartir una serie de síntesis parciales, dando cuenta de nuestro propio proceso de trabajo de investigación colectivo en el área de investigación de "entramados comunitarios y formas de lo político" en México.

En primer lugar, partimos de preguntarnos: ¿Qué significa y qué implica defender la vida, en medio de las renovadas dinámicas de apropiación, separación y mediación que las violentas lógicas de acumulación capitalista impulsan sin parar? ¿Qué se juega en aquellas luchas que, al tiempo de defender y producir un conjunto de bienes y ámbitos de vida comunes, están poniendo el horizonte político de la defensa de la vida en el centro de sus disputas?

Para ahondar en estas inquietudes, en diálogo con la perspectiva de la ecología-mundo, la ecología política latinoamericana y la apuesta de algunos feminismos, nos preguntamos por las implicaciones que tiene pensar desde la condición de interdependencia inscrita en el corazón de la vida toda. En esa dirección, el tejido de la vida es una metáfora que recuperamos porque sintetiza, con un gran potencial narrativo, una comprensión sistémica de la vida en la que todos los miembros de una comunidad ecológica se hallan interconectados en una vasta e intrincada red de relaciones inconmensurablemente compleja que se va produciendo a sí misma como resultado de las interacciones entre diversas especies y mundos de vida.

La civilización capitalista, de la mano de la violencia de las abstracciones cartesianas (Moore, 2020, p. 37), se ha erigido sobre la negación de dichas relaciones de interdependencia, buscando asegurar los procesos de acumulación capitalista a través de la expansión de las fronteras de las zonas de apropiación y explotación del trabajo y energía de las naturalezas humanas y no humanas durante los últimos 5 siglos. En ese sentido, el diagnóstico del Capitaloceno resulta útil para comprender la raíz histórica del régimen de relaciones de la (necro)economía extractivista y las bases bio-geoecológicas que han estructurado y garantizado la reorganización capitalista, patriarcal y colonial de la condición de interdependencia.

Es en estas condiciones de asimetría y de poder desigual en las que vienen emergiendo múltiples experiencias de lucha en defensa de la vida en América Latina que ponen en cuestión los términos bajo los cuales el capitalismo busca configurar el tejido de la vida para garantizar la lógica de valor. En estos contextos de conflictividad, la producción de lo común es un proceso de regeneración y reapropiación de las capacidades políticas para gestionar la vida bajo otros patrones de relacionamiento y disputar otros términos de la existencia que revitalicen y materialicen relaciones de interdependencia de otro tipo.

En los tiempos oscuros por los que atravesamos, la multiplicidad de luchas en defensa de la vida que sacuden a los territorios latinoamericanos nos invita a mirar e intervenir desde una perspectiva política centrada en la reproducción de la vida que se busca hacer cargo de las 
necesidades de regeneración parcial de los daños capitalistas, patriarcales y coloniales en el tejido de la vida.

\section{Referencias}

Apffel-Marglin, F. (septiembre, 20I8). La colonialidad de las raíces de la modernidad occidental. Ponencia presentada en la Primera Conferencia Norte-Sur sobre Decrecimiento, Ciudad de México.

Bastista Medina, J. A. (septiembre, 20I4). La concepción y la gestión 'modernas' del agua. Un ejemplo de asimilación cultural. Ponencia presentada en las XIV Jornadas de Economía Crítica: perspectivas económicas alternativas, Valladolid.

Cabnal, L. (2010). Acercamiento a la construcción del pensamiento epistémico de las mujeres indígenas feministas comunitarias de Abya Yala. Feminismos diversos: el feminismo comunitario. ACSUR-Las Segovias.

Caffentizis, G. (1995). The Fundamental Implications of the Debt Crisis for Social Reproduction in Africa. En Dalla Costa, M.y Dalla Costa, G. (Eds.). Paying the Price.Women and the Politics of International Economic Strategy (Pp. |5-4I). Zed Books.

Capra, F. (1999). La trama de la vida. Una perspectiva de los sistemas vivos. Editorial Anagrama.

Carsolio Ramírez, V. (2020). Claves para comprender la dimensión especista en la coproducción de la vida. Revista Latinoamericana de Estudios Críticos Animales, Año VII (I), 380-398. http://revistaleca.org/journal/index.php/ RLECA/article/view/I94.

Composto, C.y Navarro Trujillo, M. L. (Coords.) (20I4). Territorios en disputa. Despojo capitalista, luchas en defensa de los bienes comunes naturales y alternativas emancipatorias para América Latina. Bajo Tierra Ediciones.

Cruz, D. y Bayón, M. (2020). Cuerpos, Territorios y Feminismos. Compilación latinoamericana de teorías, metodologías y prácticas políticas. Instituto de Estudios Ecologistas el Tercer Mundo, Ediciones Abya Yala, Bajo Tierra Ediciones y Libertad Bajo Palabra.

De Angelis, M. (20/2). Marx y la acumulación primitiva: el carácter continuo de los cercamientos capitalistas. Revista Theomai, 26. 16-35. http://www.revista-theomai.unq.edu.ar/NUMERO\%2026/De\%20Angelis\%20-\%20 Marx\%20y\%20la\%20acumulaci\%C3\%B3n\%20primitiva.pdf.

Echeverría, B. (1989). Quince tesis sobre modernidad y capitalismo. Cuadernos Políticos, 58, 4I-62. Editorial Era. http:// www.cuadernospoliticos.unam.mx/cuadernos/contenido/CP.58/CP58.4I.BolivarEcheverria.pdf.

Federici, S. y Caffentzis, G. (2019). Comunes contra y más allá del capitalismo. El Apantle, Revista de Estudios Comunitarios: Producir lo común. Entramados comunitarios y luchas por la vida, pp. 45- 58. Traficantes de Sueños.

Federici S. (2010). Calibán y la Bruja. Mujeres, cuerpo y acumulación originaria. Traficantes de Sueños.

Foster, J. B. (2000). La Ecología de Marx. EIViejo Topo.

Georgescu Roegen, N. (1996). Economía y Naturaleza.Visor Distribuciones.

Gutiérrez Aguilar, R. (2017). Horizontes comunitario- populares. Producción de lo común más allá de las políticas estadocéntricas. Traficantes de Sueños.

Gutiérrez Aguilar, R. Navarro Trujillo, M. L. y Linsalata, L. (2017). Repensar lo político, pensar lo común. Claves para la discusión. En Inclán, D., Linsalata, L., Millán, M., Modernidades Alternativas (pp. 377- 4I8). UNAM-Ediciones del Lirio.

Gutiérrez Aguilar, R.y Navarro M. L. (2019). Producir lo común para sostener y transformar la vida: algunas reflexiones desde la clave de la interdependencia. Confluências, Revista interdisciplinar de Sociologia e Direito, 2 I (2), 228-324. https://doi.org/I 0.22409/conflu.v2Ii2.347/0.

Haraway, D. (2016). El Manifiesto de las especies de compañía. Sans Solei ediciones.

Hernando,A. (2012). La Fantasía de la individualidad. Sobre la construcción sociohistórica del sujeto moderno. Katz Editores. Hernández Hernández, J, (2019). Vida, muerte y lucha en la Sierra Norte de Puebla. Una reflexión en torno a la Asamblea de los Pueblos Maseual,Totonaku y Mestizo en Defensa de laVida y el Territorio. (Tesis de maestría). Benemérita Universidad Autónoma de Puebla, Puebla.

Linsalata, L. (2016). Lo comunitario-popular en México: desafios, tensiones y posibilidades. Instituto de Ciencias Sociales y Humanidades "Alfonso Vélez Pliego", Benemérita Universidad Autónoma de Puebla.

Linsalata, L. (2017). De la defensa del territorio maseual a la reinvención comunitario-popular de la política: crónica de una lucha. Estudios Latinoamericanos,40, I 17-136. http://www.revistas.unam.mx/index.php/rel/article/ view/6I595

Linsalata, L. (2019). Repensar la transformación social desde las escalas espacio-temporales de la producción de lo común. El Apantle, Revista de Estudios Comunitarios: Producir lo común, Entramados comunitarios y luchas por la vida, I I I- | 20. Traficantes de Sueños.

Linsalata, L. (2020). iNuestra lucha es por la vida! Apuntes críticos sobre la reorganización capitalista de la condición de interdependencia. Trabalho necessário, 36, 44-68. https://doi.org//0.22409/tn.vl8i36.42784.

Lovelock,J.y Margulis L. (2018). Día de la Tierra. La hipótesis de Gaia, todos somos parte de un súper organismo. Recuperado de: https://www.ecoportal.net/temas-especiales/educacion-ambiental/dia_de_la_tierra-_la_hipotesis_de_ gaia/ (23.I I.2020) 
Marx, K. (1975 [1867]). El Capital, Libro I. Siglo XXI.

Machado Aráoz, H. (2020). Seminario virtual Lecturas sobre la pandemia BP Construyendo Comunidad, junio 2020. Recuperado de:

https://www.youtube.com/watch?v=AYa48kzHkHg\&feature=share\&fbclid=IwAR I KXuzZCGGrEYoiXFDla5AhkW2a XN9LnxxVZBqcnGtZUZ- OXWfIDQIQEc_(23.II.2020)

Machado Aráoz, H. (2017). "La insustentabilidad del Capital. Ecología Política del Sur, crisis ecológico/civilizatoria y la cuestión de las Alternativas”. En Eschenhagen M. L. y Maldonado C. E., (Eds.), Epistemologías del sur para germinar alternativas al desarrollo. Debate entre Enrique Leff, Carlos Maldonado y Horacio Machado (pp. I25-I8I). Editorial de la Universidad del Rosario- Universidad Pontificia Bolivariana.

Machado Aráoz, H. (2016). Ecología política de los regímenes extractivistas. De reconfiguraciones imperiales y reex-sistencias decoloniales en Nuestra América. Revista Bajo el Volcán, 23, I|-51. Benemérita Universidad Autónoma de Puebla. https://www.redalyc.org/articulo.oa?id=28643473002.

Machado Aráoz, H. (20I4). Potosí, el origen. Genealogía de la minería contemporánea. Mardulce.

Machado Aráoz, H. (20I2). Crisis ecológica, extractivismo y necroeconomía, la religión oficial del capital. Onteaiken, I3, 19-24. Centro de Estudios Avanzados (UNC). http://onteaiken. com.ar/ver/boletin I 3/I-3.pdf

Machado Aráoz, H. (2019). Las herencias de Occidente. Crisis ecológica, colonialismo y hambre, Revista Arenas, 3, I-25. https://www.academia.edu/I I872485/Las_herencias_de_Occidente.

Margulis, L. (2002). Planeta Simbiótico. Editorial Debate.

McBrien, J. (2016). Accumulating Extinction: Planetary Catastrophism in the Necrocen. En Moore, Jason (Ed.). Anthropocene or Capitalocene? Nature, History and the Crisis of Capitalism (Pp. I I6-I37). PM Press.

Mies, M. (2019). Patriarcado y acumulación a escala mundial. Traficantes de sueños.

Moore, J.W. (2020). El Capitalismo en la Trama de la Vida. Ecología y Acumulación de Capital. Traficantes de Sueños.

Navarro Trujillo, M. L. y Machado Aráoz, H. (2020). La trama de la vida en los umbrales del Capitaloceno. El pensamiento de Jason W. Moore. Bajo Tierra Ediciones.

Navarro Trujillo, M. L. (2020a). Interdependencia de la vida humana/ no-humana: COVID 19 e hipótesis en disputa. Pensar la pandemia. Observatorio social del Coronavirus. CLACSO. https://www.clacso.org/interdependencia-dela-vida-humana-no-humana-covid- I9-e-hipotesis-en-disputa/.

Navarro Trujillo, M. L. (2020b).Violencia biocida sobre los cuerpos-territorios en resistencia en la Cuenca Alta del río Santiago. Diálogos ambientales, año I, 2, 43-48. https://www.gob.mx/cms/uploads/attachment/file/5586I2/7_ Violencia_biocida_web.pdf.

Navarro Trujillo, M. L. y Gutiérrez Aguilar, R. (20I8). Claves para pensar la interdependencia desde la ecología y los feminismos. Revista Bajo el Volcán, 28, 45-57. ICSyH, BUAP. http://www.apps.buap.mx/ojs3/index.php/bevol/ article/view/III3.

Navarro Trujillo, M. L. (20I5). Luchas por lo común. Antagonismo social contra el despojo capitalista de los bienes naturales en México. ICSyH y Bajo Tierra Ediciones.

Organización Mundial de la Salud (12.07.2017). 2100 millones de personas carecen de agua potable en el hogar y más del doble no disponen de saneamiento seguro. Recuperado de: https://www.who.int/es/news-room/detail//207-20 I 7-2-I-billion-people-lack-safe-drinking-water-at-home-more-than-twice-as-many-lack-safe-sanitation (10.10.2020).

Pérez Orozco,A. (20I4). Subversión femenina de la economía.Traficantes de Sueños.

Rátiva Gaona, S. (2019). El poder del agua. Gestión comunitaria del agua y lucha popular contra las separaciones capitalistas. (Tesis de maestría), Benemérita Universidad Autónoma de Puebla.

Swyngendouw, E. (20I I). ¡La naturaleza no existe! La sostenibilidad como síntoma de una planificación despolitizada. Urban, I, pp. 4I-56. Universidad Politécnica de Madrid. http://polired.upm.es/index.php/urban/article/ viewFile/4I0/I877.

Wedekind, J. y Milanez, F. (2017). Del Capitaloceno a una nueva política ontológica: Entrevista a Jason W. Moore. Ecología Política, 53, I08-I I0. https://www.ecologiapolitica.info/?p=9795. 


\section{RELACIONES INTERNACIONALES}

Revista académica cuatrimestral de publicación electrónica Grupo de Estudios de Relaciones Internacionales (GERI)

Universidad Autónoma de Madrid, España

https://revistas.uam.es/relacionesinternacionales

ISSN 1699 - 3950

f facebook.com/RelacionesInternacionales

3. twitter.com/RRInternacional 